\title{
Properties and Applications of a New Chemical Grouting Material
}

\author{
Xiaohua Yang $\mathbb{D},{ }^{1}$ Kunlong Zheng $\mathbb{D},{ }^{2}$ Lixiao $\mathrm{Xu},{ }^{3}$ and Nieyangzi Liu ${ }^{2}$ \\ ${ }^{1}$ Key Laboratory for Bridge and Tunnel of Shaanxi Province, Chang'an University, Xi'an 710064, Shaanxi, China \\ ${ }^{2}$ School of Highway, Chang'an University, Xi'an 710064, Shaanxi, China \\ ${ }^{3}$ Zhejiang Provincial Institute of Communications Planning, Design \& Research Co., Ltd., Hangzhou 31008, Zhejiang, China
}

Correspondence should be addressed to Kunlong Zheng; kunlongzheng@163.com

Received 30 July 2019; Revised 19 January 2020; Accepted 25 February 2020; Published 30 June 2020

Academic Editor: Venu G. M. Annamdas

Copyright (C) 2020 Xiaohua Yang et al. This is an open access article distributed under the Creative Commons Attribution License, which permits unrestricted use, distribution, and reproduction in any medium, provided the original work is properly cited.

\begin{abstract}
The study investigates a new chemical grout by mixing the main agent, auxiliary agent, catalyst, foam stabilizer, solvent, and water, to treat the distress of railway tunnel. The orthogonal design was used to obtain 16 groups of grout proportion schemes, and reasonable proportion parameters were screened using laboratory and field tests. Additionally, this study included detailed research on the grout performance. The test results showed that the proportion schemes of groups 3, 4, and 15 grout were the most reasonable. In particular, for group 3, the viscosity is $663 \mathrm{MPa} \cdot \mathrm{s}$, the curing time is $119 \mathrm{~s}$, the foaming capacity is $1589 \%$, and the compressive strength is $20.16 \mathrm{MPa}$. For group 4, the viscosity is $663 \mathrm{MPa} \cdot \mathrm{s}$, the curing time is $137 \mathrm{~s}$, the foaming capacity is $1809 \%$, and the compressive strength is $17.76 \mathrm{MPa}$. For group 15, the viscosity is $281 \mathrm{MPa} \cdot \mathrm{s}$, the curing time is $98 \mathrm{~s}$, the foaming capacity is $1173 \%$, and the compressive strength is $26.79 \mathrm{MPa}$. Groups 4 and 15 grouts were used to treat the frost boiling and track bed subsidence in existed railway tunnels. Based on this, field monitoring showed that muddy water became clear water with an average depth of only $4 \mathrm{~mm}$ in the drainage ditch and that the irregular subsidence of the track bed was also solved after treatment. According to the aforementioned experimental research and analysis, it is proven that new grout not only exhibits a reasonable solidification time, high strength, and excellent waterproofing and impermeability with no pollution of the environment but also can be produced by a safe and convenient synthesis method. Group 4 is suitable for treating tunnel seepage, group 15 is suitable for structural reinforcement, and group 3 confers the advantages of seepage prevention, leakage stoppage, and reinforcement.
\end{abstract}

\section{Introduction}

As a common way to treat the existed railway tunnel distress, the grout method requires reasonable selection of materials and technology to effectively solve problems and achieve an ideal grouting effect $[1,2]$. At present, there are numerous varieties of grout materials, which can be roughly divided into two categories: nonchemical materials and chemical materials [3-5]. Specifically, the nonchemical grout materials principally include cement, clay, bentonite grout, and so on $[6,7]$. Some researchers studied the strength deterioration and change in the service life of these cement-based grout materials in seawater erosion environments by using the grey correlation theory and multielement grey prediction model [8]. To obtain high-performance cement grout, Sowmini and Anand mixed cement, ultrafine slag, superplasticizer, and water to develop a superfine slag-modified cement grout. Laboratory tests showed that the slag can effectively reduce the bleeding of cement grout, improve the compressive strength, and reduce the shrinkage of consolidation [9]. Yoon and El Mohtar studied the performance and application of sodium pyrophosphate bentonite grout and carried out numerical research on granular soil. According to the relationship between the volume of grouting hole and lumped parameters, a new grout performance index of bentonite is proposed [10]. Because many pores in the excavation damage zone (EDZ) are connected with the excavation face, grouting into EDZ is very difficult. Masumoto et al. conducted the clay grout in situ injection test for EDZ adjacent to the clay bulkhead and evaluated the ability of clay grout to reduce EDZ permeability through the field test [11]. The chemical grout materials included water glass, polyurethane, epoxy resin, and organic polymer composite grout, among other materials [12-14]. Yang and 
Yu have not only researched on the properties of cementwater glass grout at different ratios and temperatures but also determined the reasonable parameter ratios to obtain grout with the high strength and poor self-stability, which was applied in loess tunnel construction [15]. Using a combination of polymer rheological dynamics, fluid mechanics, and numerical analysis, Wang et al. studied the grout plugging process, mechanism of action on tunnel surrounding rock, and grout technology based on the research of non-water-reactive polymer grout materials properties used to solve the problems of underground engineering construction [16]. Li et al. analysed the reinforcement mechanism of Melisan, a new chemical grout material, studied its physicochemical characteristics in detail through laboratory testing, and obtained the proper proportion and relative specifications of new grout. Compared with the same common grout materials, Melisan exhibits a rapid reaction, high strength, good scouring resistance, an innocuous nature, and excellent performance with respect to permeability and hydroexpansiveness [17]. Hydrophilic polyurethane grout was studied under controlled volume change with various water-to-grout ratios by Vipulanandan, M. Burak Kazez, and S. Henning. It was observed that the maximum pressure decreased with increasing water-togrout ratios and volume expansion during the foaming process. Therefore, the water-to-grout ratios and volume expansion of hydrophilic polyurethane grout have been related to the maximum pressure and temperature increases during curing [18]. On the basis of grout treatment of leakage tunnels during the operational period, researchers conducted a comparative study on the properties of four conventional grout materials: ordinary Portland cement, cement-sodium silicate, ultrafine cement, and a polymer. The results showed that the ordinary cement grout is suitable for grouting in the cavity behind tunnel, cement-sodium silicate grout is suitable for water plugging in leakage areas with large groundwater flow and high water pressure, and ultrafine cement is suitable for micropore and fissure seepage areas, while the polymer cement is suitable for seepage treatment in fissure-intensive areas [19].

Due to the short "skylight" time of existed railway tunnels and limited internal construction space, grout materials with short solidification time, good waterproofing, and impermeability, as well as rapid and stable strength improvement, should be selected for construction to ensure the safe operation of trains [20-22]. Although numerous grout materials and various applications were developed, it still lacked a grout that can not only prevent seepage and leaks but also reinforce the structure for treating distresses such as existed railway tunnel seepage and subsidence of track beds. Therefore, this paper created a new chemical grout by using some solvents such as polyaryl polymethylene isocyanate, polyether polyol, triethylamine, dibutyltin dilaurate, and polysiloxane-polyoxyolefin as raw materials. The new grout material has a reasonable reaction time, good cohesiveness, high strength, excellent waterproofing and impermeability, and environmentally friendly and that can be safely and rapidly synthesized and subsequently used for tunnel construction site preparation. In this paper, we used an orthogonal design method and laboratory tests to research the proportion scheme and performance in detail to obtain the optimal proportioning and performance of the grout. Engineering field tests of the grout to determine whether it can treat tunnel seepage and other distress were also conducted.

\section{Raw Material of Grout}

The main agent, auxiliary agent, catalyst, foam stabilizer, and other solvents were used to produce the new chemical grout. The following is a detailed description of the selection and determination of various raw materials.

2.1. Selection of Primary Agent. The main agent of grout is the polyisocyanate solution. Numerous polyisocyanates are known. Among them, the most commonly included ones are toluene diisocyanate (TDI), 4,4'-methylene diphenyl diisocyanate (MDI), and polyaryl polymethylene isocyanate (PAPI). TDI is prepared by nitration of toluene to dinitrotoluene, which is then reduced to toluenediamine and reacted with phosgene. MDI is made from the photochemical reaction of aniline and formaldehyde after condensation. The two -NCO groups in MDI are far away from each other, when one-NCO participates in the reaction and the other remains active. As a result, the reactivity of MDI is higher than TDI. PAPI, a polyisocyanate mixture with different functionalities, is made by mixing 50\% MDI with $50 \%$ polyisocyanates with functionality greater than 2 . The performance comparison of three materials is shown in Table 1.

Through analysis and comparison, it can be found that TDI and MDI have small molecular weights, low viscosities, and high (-NCO) contents as well as high reactivity. However, they are both highly toxic. PAPI has a highmolecular weight, high viscosity, mild reactivity, low toxicity, fire resistance, and good high-temperature resistance. Given the advantages and disadvantages of the three materials, the main agent of new grout is the polyaryl polymethylene isocyanate (PAPI), with the model PAPI*135C Polymeric MDI.

2.2. Selection of Auxiliary Agent. The selection range of the grout auxiliary agent is either polyether or polyester resin. The polyether resin is prepared by polyaddition of an initiator containing active hydrogen groups with ethylene oxide (EO), propylene oxide (PO), or butylene oxide (BO) under the action of a catalyst, while the polyester resin is a high-molecular compound formed by polycondensation of dihydric alcohol with a dihydric acid or polyhydric alcohol with a polybasic acid. The aqueous stability and viscosity of polyether resin are greater and lower than those polyester resin, respectively, making polyether resin more conducive to the diffusion of materials in structures and injected media.

Based on characteristics of the two materials, we selected a mixture of polyether polyols 4110 and 6110, with a hydroxyl value of $470 \pm 20(\mathrm{mg} \mathrm{KOH} / \mathrm{g})$ and viscosity of 
Table 1: Performance comparison table of materials.

\begin{tabular}{lccccc}
\hline Material & Formula weight & Content of - NCO (\%) & Viscosity (MPa.s) & Activity & Toxicity \\
\hline TDI & 174.16 & 48 & 2.44 & High & Strong \\
MDI & 250.24 & 33.6 & 6.30 & Moderate & Moderate \\
PAPI & $350 \sim 420$ & 28 & $100-250$ & Mild \\
\hline
\end{tabular}

$4000 \pm 500 \mathrm{MPa} \cdot \mathrm{s}\left(\right.$ at $25^{\circ} \mathrm{C}$ ), as the auxiliary agent of the new grout.

2.3. Selection of Catalyst. The catalyst can promote the reaction between the $-\mathrm{NCO}$ radical in the main agent and water to generate a large amount of carbon dioxide, enabling the grout permeability and curing time to reach an optimal balance effect and improve the grouting diffusion range. Additionally, it can promote the reaction of $-\mathrm{NCO}$ with hydroxyl groups in polyols to increase the lengths of molecular bonds and accelerate the solidification rate of materials. To reasonably control the reaction time and ensure that the grout flows into the pores and cracks in the structure as much as possible during the grouting process, the material mainly selects the mixture of tertiary amine and tin salt as the catalyst to achieve a good catalytic reaction effect, and the ideal specific type is the combination of triethylamine and dibutyltin dilaurate.

2.4. Selection of Foam Stabilizer. Foam stabilizer can not only promote the mutual dissolution and emulsification of raw materials and affect the generation, distribution, and stability of foam but can also make the structure and size of foam more uniform and control the expansion rate of grout. At present, the most commonly used foam stabilizer is the polysiloxane-polyoxyalkylene ether copolymer. The molecular structure of this material includes both hydrophilic and hydrophobic groups, which makes it easier to combine with various raw materials for polyurethane preparation, and thus forms a homogeneous reaction system. Therefore, to prepare and create the grout with the best performance, we selected the polysiloxane-polyoxyalkylene ether copolymer as the foam stabilizer.

2.5. Selection of Solvent. Solvents are usually added to grouts to reduce their viscosity and improve the fluidity. Xylene solution was selected as solvent to be added to the raw material. At the same time, to better induce the reaction, 3\% water based on the total mass of the mixture of the primary agent and auxiliary agent should be added to function as an inducing agent.

Through the aforementioned analysis and conclusions, the raw materials of new grout were determined. Specifically, the main agent is polyaryl polymethylene isocyanate PAPI*135C Polymeric MDI, the auxiliary agent is a mixture of polyether polyol 4110 and polyether polyol 6110, the catalyst is triethylamine and dibutyltin dilaurate, the foam stabilizer is polysiloxane-polyoxyalkylene ether copolymer, the solvent is xylene solution, and the reaction-inducing agent is water.

\section{Test Methods}

In order to get the reasonable grout proportion scheme and determine the performance parameters under each ratio condition, the grout proportion and performance tests were designed.

3.1. Grout Proportion Schemes. The orthogonal test methodology was used to research and design the mixture ratio of new grout. Four factors were selected: mass ratios of main and auxiliary agents, amount of catalyst, amount of foam stabilizer, and amount of solvent. Mass ratios of main and auxiliary agents were $1: 1,2: 1,3: 1$, and $4: 1$, respectively; the amount of catalyst was $0.5 \% \sim 3.0 \%$ of the total mass of agent mixture, the amount of foam stabilizer was $0.5 \%$ $2.0 \%$, the amount of solvent was $5 \% \sim 20 \%$, and the amount of reaction inducer was $3 \%$. Therefore, the $L_{16}\left(4^{5}\right)$ four-level table was selected for scheme design. The specific grout proportion ratio scheme is shown in Table 2.

The new chemical grout was a binary grout, which was made by mixing $\mathrm{A}$ and $\mathrm{B}$ liquids. According to Table 2, liquids $\mathrm{A}$ and $\mathrm{B}$ were prepared. Liquid $\mathrm{A}$ was a mixture of main agent, solvent, and reaction inducer, and liquid $B$ was a mixture of auxiliary agent, catalyst, and foam stabilizer. The prepared liquids $\mathrm{A}$ and $\mathrm{B}$ were put into different containers and mixed when needed. The grout can be prepared according to the abovementioned methods in the laboratory test or be prepared by using the binary grout injector in situ.

3.2. Grout Performance Tests. On the basis of the proportion schemes and preparation method in the previous section, 16 kinds of grout were prepared. Referring to the requirements of various specifications, the density, viscosity, cutting time, foaming capacity, unconfined compressive strength, and environmental performance of new grout are studied in detail. The specific experimental contents are shown in Table $3[23,24]$.

3.3. Specimen Preparation and Testing Methods. According to the standard requirements shown in Table 3, the grout performance was studied using various test instruments :

(1) The density of new grout with different proportion ratios was determined by Beaume hydrometer and precision densimeter, according to the Chinese standard GB/T 8077-2012.

(2) The viscosity of new grout was determined by using rotational viscosimeter, according to the Chinese standard GB/T 2794-2013.

(3) In accordance with the Chinese standard JC/T 20412010, curing time and foaming capacity of new grout 
TABLE 2: Orthogonal design table.

\begin{tabular}{|c|c|c|c|c|}
\hline \multirow{2}{*}{ Group } & \multicolumn{4}{|c|}{ Variable } \\
\hline & Main agent: auxiliary agent & Catalyst amount (\%) & Foam stabilizer amount (\%) & Solvent amount (\%) \\
\hline Group 1 & $1: 1$ & 0.0 & 0.5 & 5 \\
\hline Group 2 & $1: 1$ & 0.25 & 1.0 & 10 \\
\hline Group 3 & $1: 1$ & 0.5 & 1.5 & 15 \\
\hline Group 4 & $1: 1$ & 0.75 & 2.0 & 20 \\
\hline Group 5 & $2: 1$ & 0.0 & 1.0 & 15 \\
\hline Group 6 & $2: 1$ & 0.25 & 0.5 & 20 \\
\hline Group 7 & $2: 1$ & 0.5 & 2.0 & 5 \\
\hline Group 8 & $2: 1$ & 0.75 & 1.5 & 10 \\
\hline Group 9 & $3: 1$ & 0.0 & 1.5 & 20 \\
\hline Group 10 & $3: 1$ & 0.25 & 2.0 & 15 \\
\hline Group 11 & $3: 1$ & 0.5 & 0.5 & 10 \\
\hline Group 12 & $3: 1$ & 0.75 & 1.0 & 5 \\
\hline Group 13 & $4: 1$ & 0.0 & 2.0 & 10 \\
\hline Group 14 & $4: 1$ & 0.25 & 1.5 & 5 \\
\hline Group 15 & $4: 1$ & 0.5 & 1.0 & 20 \\
\hline Group 16 & $4: 1$ & 0.75 & 0.5 & 15 \\
\hline
\end{tabular}

TABLE 3: Grout performance test.

\begin{tabular}{lcc}
\hline Grout test & Key instrument & Test method \\
\hline Density & Beaume hydrometer, precision densimeter, etc. & Reference to GB/T 8077-2012, 7.3 \\
Viscosity & Rotational viscosimeter, etc. & Reference to GB/T 2794-2013 \\
Curing time & Balance, glass cylinder, beaker, stopwatch, etc. & Reference to JC/T 2041-2010, 7.6 \\
Foaming capacity & Balance, glass cylinder, beaker, etc. & Reference to JC/T 2041-2010, 7.11 \\
Unconfined compressive strength & Self-made moulding-die, universal test machine, etc. & Reference to GB/T 1041 2008 \\
Environmental protection & Balance, analysis meter, etc. & Reference to GB 5750-2006 \\
\hline
\end{tabular}

were determined. After pouring liquids A and B with different ratios into a beaker, the mixture was quickly stirred 3 to 5 times using a glass rod. Then, the grout was tested in accordance with the abovementioned specification.

(4) The grout solidification was made by self-made specimen mould (Figure 1) that was used in unconfined compression strength test [25]. The sizes of specimen were $50 \mathrm{~mm}$ in diameter and $100 \mathrm{~mm}$ in height (Figure 2). The organic silicon release was sprayed inside mould evenly. Rubber rings were used placed at the upper and the lower cover of mould, which could effectively prevent grout loss that was caused by its expansion. After the lower seal cover was installed on mould, then the prepared liquids A and B were poured into mould and stirred 3 to 5 times rapidly. As grout expanded near the top of mould, the upper seal cover was covered immediately. After completion of grout reaction, the solidification sample was taken out. The specimens were cured about $168 \mathrm{~h}$ under standard test condition and then tested by universal testing machine with $500 \mathrm{~N} / \mathrm{s}$ loading rate.

(5) After grout solidification, specimens were immersed in water for more than seven days, and the different aqueous solution was analysed. The test results were used to study the environmental impact of new chemical grout.

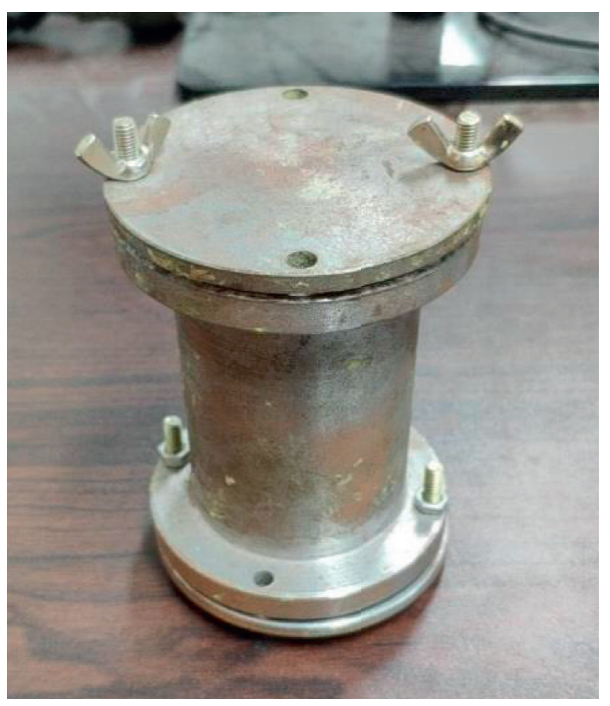

FIgURE 1: Self-made specimen mould.

\section{Results and Discussion}

4.1. Density of Grout. The density of the mixture of main and auxiliary agents was tested according to the test design requirements, and the results are shown in Table 4 .

According to the requirements of standard JC/T 20412010 "Polyurethane Grouting Material," the density of oily 


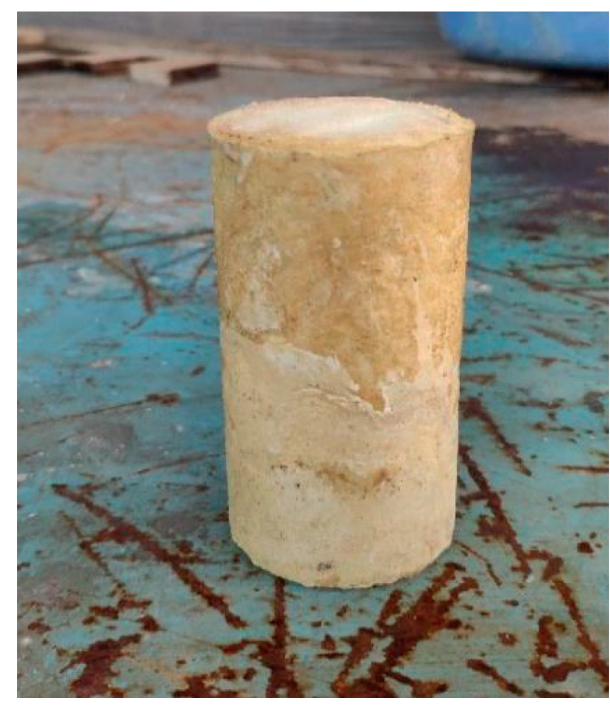

FIgURE 2: Grout solidification.

TABLE 4: Test results of grout density.

\begin{tabular}{lcccc}
\hline Ratio & $1: 1$ & $2: 1$ & $3: 1$ & $4: 1$ \\
\hline Density $\left(\mathrm{g} / \mathrm{cm}^{3}\right)$ & 1.207 & 1.226 & 1.235 & 1.241 \\
\hline
\end{tabular}

polyurethane grout should meet the standard of $\rho \geq 1.05 \mathrm{~g} /$ $\mathrm{cm}^{3}$. The data in Table 4 show that, although the mixing ratio of mixture is changing, the grout density is always greater than $1.05 \mathrm{~g} / \mathrm{cm}^{3}$. Thus, the density can satisfy the standard requirements. The performance of the new grout can be further studied to determine the optimal mixing scheme.

4.2. Viscosity of Grout. The viscosity of the mixture of main and auxiliary agents was tested according to test design requirements, and the results are shown in Table 5.

According to the requirements of standard JC/T 20412010, the viscosity of grout should be less than $1.0 \times 10^{3} \mathrm{MPa} \cdot \mathrm{s}$. The results in Table 5 show that, although the mixing ratio of main and auxiliary agents is changing during the test, the viscosity is always less than $1.0 \times 10^{3} \mathrm{MPa} \cdot \mathrm{s}$. As a result, the grout viscosity values of the four proportion schemes meet the requirements. Therefore, the performance of new grout can be further studied according to the standard to determine the optimal proportion scheme.

4.3. Curing Time of Grout. According to test design requirements, curing time of new grout was tested, and the test results are shown in Table 6.

The curing time of grout is greatly affected by the amount of catalyst and reaction temperature, while the curing time can directly affect the diffusion range and grouting effect. From the test results in Table 6, groups 5, 9, and 13 did not achieve sufficient time and should be ruled out. The times of groups 7,8 and 12 were very short. If the grout solidifies too quickly, the diffusion range will be small and the grouting pipe may also become blocked. Therefore, they should be ruled out
TABLe 5: Test results of grout viscosity.

\begin{tabular}{lllll}
\hline Ratio & $1: 1$ & $2: 1$ & $3: 1$ & $4: 1$ \\
\hline Viscosity (MPa.s) & 663 & 579 & 416 & 281 \\
\hline
\end{tabular}

as well. When the main agent, auxiliary agent, and various additives are mixed and stirred evenly, the end groups of the isocyanate react with water to form organic macromolecular products. At the same time, they will continue to react with carbamate bonds on the main chain to form macromolecular carbamates, and the grout can then be finally consolidated through series of chemical reactions. The main equations of the reactions in the process are shown as follows:

$\mathrm{OCN}-\mathrm{R}-\mathrm{NCO}+2 \mathrm{H}_{2} \mathrm{O} \rightarrow[\mathrm{HOOCNH}-\mathrm{R}-\mathrm{NHCOOH}] \rightarrow \mathrm{H}_{2} \mathrm{~N}-\mathrm{R}-\mathrm{NH}_{2}+\mathrm{CO}_{2} \uparrow$

2nOCN-R-NCO+nH${ }_{2}$ N-R-NH $\mathrm{N}_{2} \rightarrow$ fOCN-R-N-C-N-R-NHC-NH-R-NC $f_{n}$

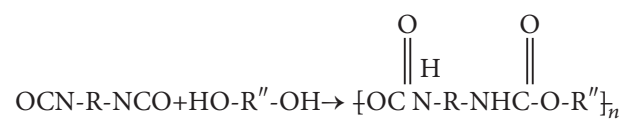

Although the six testing groups of 5, 7, 8, 9, 12, and 13 have been ruled out, the curing times of the remaining ten groups are relatively reasonable and suitable for grout diffusion in the injected medium. The specific mixing ratio still needs to be studied through subsequent tests. Consequently, the ratios of the ten testing groups $1,2,3,4,6,10,11,14,15$, and 16 were tested further.

4.4. Foaming Capacity of Grout. According to test design and test results of curing time, the grout foaming capacity was studied. The test results are shown in Table 7.

According to the requirements of standard JC/T 20412010 , the foaming rate of grout should be $\geq 1000 \%$. As shown in Table 7, the foaming capacity of groups 1, 2, 6, 11, and 16 is all less than $1000 \%$, so these groups should be eliminated. The foaming capacities of groups 10 and 14 are $2575 \%$ and $2476 \%$, respectively, which is very high. Too high foaming capacities of grout may not only damage internal structure of the injected medium but also reduce the strength of solidification itself. Therefore, they are eliminated as well. The foaming capacity directly affects the expansion ratio and secondary permeability of grout. Chain extension reaction occurs when the raw materials meet water, and then $\mathrm{CO}_{2}$ is released during reaction. The chain extension reaction can prolong the molecular chains of polymer. As the reaction proceeded, cross-linking reaction occurs: isocyanate groups between molecular chains form covalent bonds and branched cross-links through cross-linking agents, which make linear molecules become reticular molecules and enable materials to form a morphology of reticular polymers. The reaction process equations for chain extension and cross-linking are shown as follows: 
TABLE 6: Test results of grout curing time.

\begin{tabular}{|c|c|c|c|c|c|c|c|c|c|c|c|c|c|c|c|c|}
\hline Group & 1 & 2 & 3 & 4 & 5 & 6 & 7 & 8 & 9 & 10 & 11 & 12 & 13 & 14 & 15 & 16 \\
\hline Curing time (s) & 310 & 163 & 119 & 137 & - & 221 & 86 & 80 & - & 164 & 110 & 79 & - & 101 & 98 & 94 \\
\hline
\end{tabular}

TABLE 7: Test results of grout foaming capacity.

\begin{tabular}{lcccccccccc}
\hline Group & 1 & 2 & 3 & 4 & 6 & 10 & 11 & 14 & 15 \\
\hline Foaming capacity (\%) & 579 & 736 & 1589 & 1809 & 846 & 2575 & 797 & 2476 & 1173 & 957 \\
\hline
\end{tabular}

2OCNR-NH-CO-O-R'-O-O-CO-NHRNCO+HOR"OH $\rightarrow$ OCN-R-NH-CO-O

OCN-R-NH-CO-O-R' -O-CO-NHRNHCO-O-R"-O-OCHNR-OC-O-R

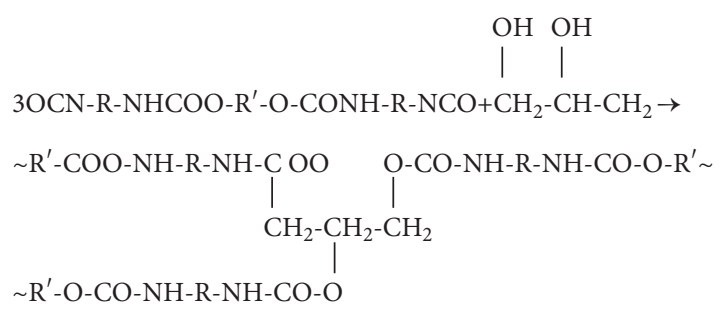

(5)

2OCN-R-NH-CO-O-R' -O-CO-NH-R-NCO+ $\mathrm{H}_{2} \mathrm{O} \rightarrow$

OCN-R-NH-CO-O-R' -O-CO-NH-R-NH

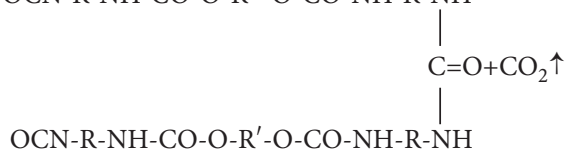

At the same time, grout will react with water to generate unstable intermediate products such as amino acids and carbon dioxide gas, and the reaction equation is shown in equation (6). When grout is injected into medium, the released $\mathrm{CO}_{2}$ can further diffuse on the basis of its own volume expansion, thus forming a secondary filling effect and pushing grout into the tiny cracks and filling the gaps tightly to improve the grouting effect. The amount of catalyst and foam stabilizer in different proportions can effectively adjust the new grout curing time and foaming behaviour, thus enabling them to reach a more balanced state and react to form a stable solidified body finally.

According to the research and analysis, the foaming capacities of groups $1,2,6,10,11,14$, and 16 did not meet the standard requirements and should be ruled out. However, the test results of groups 3, 4, and 15 were more reasonable. Consequently, the unconfined compressive strength tests of groups 3, 4, and 15 were continued to determine the optimal proportion of grout.

4.5. Unconfined Compressive Strength Test of Grout. Unconfined compressive strength of groups 3, 4, and 15 was tested, and the test results are shown in Table 8 .

From the test data in Table 8, the maximum compressive strength value is $26.79 \mathrm{MPa}$ and the minimum value is 17.76 MPa. Nevertheless, all data are much higher than the minimum compressive strength of $6 \mathrm{MPa}$ required by standard JC/T 2041-2010 for grout. Therefore, based on the
TABLE 8: Test results of grout unconfined compressive strength.

\begin{tabular}{lccc}
\hline Group & 3 & 4 & 15 \\
\hline Compressive strength $(\mathrm{MPa})$ & 20.16 & 17.76 & 26.79 \\
\hline
\end{tabular}

aforementioned test results and analysis, the new grout performance obtained by groups 3, 4, and 15 proportion schemes meets the requirements of standard.

4.6. Environmental Protection Test of Grout. Because tunnels can affect underground water system within the scope of construction, the grout will easily contact the underground water source directly. To ensure that the underground water system, soil, and environment are not polluted and that the personal health of grouting construction personnel is not harmed, the environmental performance of grout materials should appropriately be investigated to make sure it can be used safely. According to test design, the test results of various ion concentrations in the aqueous solution are shown in Table 9.

From Table 9, it can be seen that three samples' ion concentrations are below the limit values of their concentrations in drinking water. It is indicated that the environmental protection of new grout conformed to the national standard requirements of GB 5750-2006 "Sanitary Standard Test Method for Drinking Water."

Through a series of analyses and test studies, it is determined that the proportion schemes of groups 3, 4, and 15 are most reasonable. The foaming capacity of group 4 is highest, at $1809 \%$. So No. 4 grout can be effectively injected into small gaps in the structure and is suitable for treating tunnel water leakage. The compressive strength of group 15 is the highest one, at $26.79 \mathrm{MPa}$. So No. 15 grout can effectively fill and reinforce the structure and is suitable for strengthening the tunnel structure. The foaming rate and compressive strength of group $3(1589 \%$ and $20.16 \mathrm{MPa}$, respectively) are between groups 4 and 15, indicating that it can be used to treat tunnel distress requiring seepage prevention, leakage stoppage, and reinforcement.

\section{Construction and Field Experiments}

5.1. Project Profile. Through the aforementioned test study, three kinds of grout proportion schemes were determined. The next step is to study the practical engineering application of the new grout.

A railway tunnel opened in 2009. After being operated for a period of time, it is found that some sections of tunnel had water leakage and basement distress, such as basement 
TABLE 9: Detection results of ion concentration in aqueous solution.

\begin{tabular}{lcccc}
\hline \multirow{2}{*}{ Ion species } & \multicolumn{2}{c}{ Solution ion concentration $(\mathrm{mg} / \mathrm{L})$} & \multicolumn{2}{c}{ Limit concentration of drinking water (mg/L) } \\
& Group 3 & Group 4 & Group 15 & 0.05 \\
$\mathrm{As}$ & $<0.001$ & $<0.001$ & $<0.001$ & 0.005 \\
$\mathrm{Cd}$ & $<0.0001$ & $<0.0001$ & $<0.0001$ & 0.05 \\
$\mathrm{Cr}$ & $<0.0001$ & $<0.0001$ & $<0.0001$ & 0.01 \\
$\mathrm{Pd}$ & $<0.001$ & $<0.001$ & $<0.005$ & 0.001 \\
$\mathrm{Hg}$ & $<0.0001$ & $<0.0001$ & $<0.0001$ & 0.01 \\
$\mathrm{Se}$ & 0.0002 & 0.0002 & 0.0003 & 0.05 \\
$\mathrm{CN}$ & $<0.01$ & $<0.01$ & $<0.01$ & 1.0 \\
$\mathrm{~F}^{-}$ & 0.12 & 0.09 & 0.15 & 10 \\
$\mathrm{NO}_{3}{ }^{-}$ & 0.24 & 0.23 & 0.31 & 0.7 \\
$\mathrm{ClO}_{3}{ }^{-}$ & 0.16 & 0.17 & 0.21 & 250 \\
$\mathrm{SO}_{4}{ }^{-}$ & 0.21 & 0.19 & 0.34 & 0.06 \\
$\mathrm{CCl}_{4}$ & $<0.001$ & $<0.001$ & $<0.001$ & \\
$\mathrm{Al}^{3+}$ & $<0.01$ & $<0.01$ & $<0.015$ & 0.2 \\
$\mathrm{Fe}$ & $<0.07$ & $<0.07$ & $<0.07$ & 0.3 \\
$\mathrm{Mn}$ & $<0.04$ & $<0.045$ & $<0.046$ & 0.1 \\
$\mathrm{Zn}$ & $<0.044$ & $<0.045$ & $<0.044$ & 1.0 \\
$\mathrm{Smelly}$ taste & $\mathrm{Nil}$ & $\mathrm{Nil}$ & $\mathrm{Nil}$ \\
$\mathrm{pH}$ & 5.5 & 5.5 & 5.7 & $6.5 \sim 8.5$ \\
Total dissolved solids & 21 & 24 & 18 & 1000 \\
\hline
\end{tabular}

cracking, ballast sinking, and frost boiling, as shown in Figures 3 and 4 . The distress was detected and analysed by geological radar, rebound test hammer, and core sample detection, and voids, segregation, and honeycombs were found within the filling layer between track bed and inverted arch in some sections. This distress could reduce the structural strength and lead to irregular settlement of the track bed. However, the fissure water in surrounding rock seeped into tunnel structure through the honeycomb cavity, inverted arch backfill layer and backfill layer working seam, settlement seam, etc. Repeated pressure rolling of trains on aquifers then led to the frost boiling and leakage of tunnel.

5.2. Treatment of Tunnel Leakage. According to the amount of leakage and the degree of damage to the structure in railway tunnels, the lining leakage can be divided into four grades with specific quantitative indicators, as shown in Table $10[26,27]$. Some sections of the tunnel exhibited frost boiling, and the mud blocked the drainage ditch and cable trench. According to Table 10, the tunnel leakage is the second level, which is serious. Therefore, effective measures are urgently needed to address it.

To ensure that the grout enters the broken and hollow parts of the structure, grout with good permeability, high foaming capacity, and strength should be selected. The No. 4 grout, with high expansibility, strong injectability, good fluidity, a wide diffusion range, and a curing time of $137 \mathrm{~s}$ and foaming capacity of $1809 \%$ can effectively fill cracks in the structure. As a result, the No. 4 grout was used to grout between the side ditch and the cable ditch to inhibit the infiltration of fissure water.

5.3. Treatment of Track Bed Distress. To effectively fill and reinforce the track bed base, a grout with high strength, good permeability, and diffusion should be selected for the

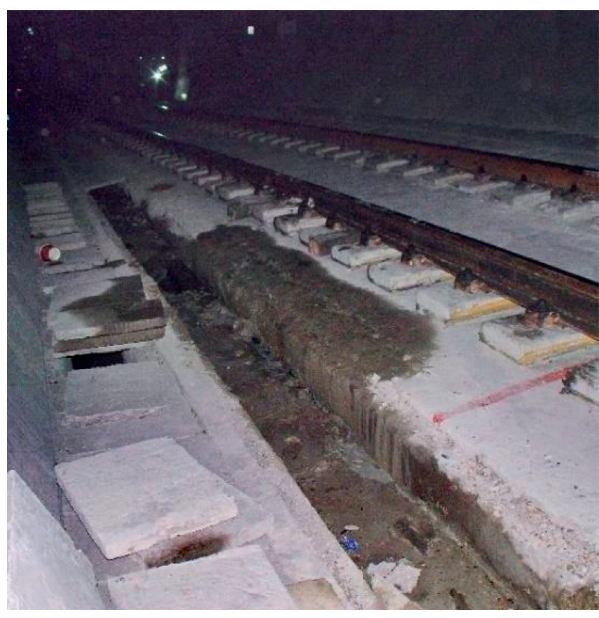

FIgURE 3: Tunnel frost boiling.

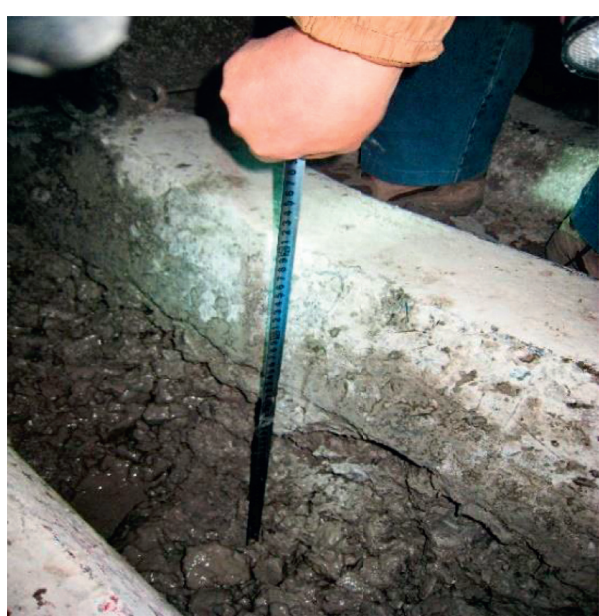

FIgURE 4: Track bed sinking. 
TABLE 10: Quantitative index of leakage distress in railway tunnels.

\begin{tabular}{|c|c|c|}
\hline $\begin{array}{l}\text { Distress } \\
\text { grade }\end{array}$ & $\begin{array}{l}\text { Classification of } \\
\text { distress }\end{array}$ & Physical truth of lining leakage \\
\hline 1 & Slight (c) & $\begin{array}{l}\text { Leakage water corrodes rails and worsens the track bed condition. Curing cycle is shortened. } \\
\text { Distress will develop to level B. }\end{array}$ \\
\hline 2 & Serious (B) & Dripping and seeping water in tunnels which cause track bed frost boiling. \\
\hline 3 & More serious $(\mathrm{AI})$ & $\begin{array}{c}\text { Tunnel vault emits water and drops into a line. Rising soil is serious, which affects the normal } \\
\text { operation. }\end{array}$ \\
\hline 4 & $\begin{array}{l}\text { Extremely serious } \\
\text { (AA) }\end{array}$ & $\begin{array}{c}\text { Water accumulates in the electric traction section. Tunnel vault leakage flows to overhead lines } \\
\text { directly. }\end{array}$ \\
\hline
\end{tabular}

TABLE 11: Tunnel leakage before and after grouting.

\begin{tabular}{|c|c|c|c|c|c|}
\hline \multirow{2}{*}{ Order number } & \multirow{2}{*}{ Sections } & \multicolumn{2}{|c|}{ Water inflow of track bed surface $(\mathrm{L} / \mathrm{d})$} & \multicolumn{2}{|c|}{ Water depth in drains $(\mathrm{mm})$} \\
\hline & & Before grouting & After grouting & Before grouting & After grouting \\
\hline 1 & $\mathrm{~K} 248+300$ & 0.5 & nil & 18 (water) & 3 (water) \\
\hline 2 & $\mathrm{~K} 250+516$ & 9 & nil & 36 (mud) & 5 (water) \\
\hline 3 & $\mathrm{~K} 251+217$ & 32 & nil & 136 (mud) & 4 (water) \\
\hline 4 & $\mathrm{~K} 251+400$ & 15 & nil & 82 (mud) & 3 (water) \\
\hline
\end{tabular}

TABLE 12: Compressive strength of trial lot before and after grouting.

\begin{tabular}{|c|c|c|c|c|c|c|}
\hline \multirow{2}{*}{ Order number } & \multirow{2}{*}{ Sections } & \multirow{2}{*}{ Invert (MPa) } & \multicolumn{2}{|c|}{ Packed layer (MPa) } & \multicolumn{2}{|c|}{ Track bed (MPa) } \\
\hline & & & Before grouting & After grouting & Before grouting & After grouting \\
\hline 1 & $\mathrm{~K} 251+025$ & 25.8 & 18.8 & 26.0 & 41.7 & 43.0 \\
\hline 2 & $\mathrm{~K} 251+060$ & 24.8 & 18.7 & 25.8 & 43.7 & 44.5 \\
\hline 3 & $\mathrm{~K} 251+190$ & 24.6 & 19.0 & 26.5 & 44.5 & 44.8 \\
\hline 4 & $\mathrm{~K} 251+217$ & - & 8.8 & 26.2 & - & 42.3 \\
\hline 5 & $\mathrm{~K} 251+227$ & 25.3 & 13.9 & 25.4 & 18.9 & 42.8 \\
\hline 6 & $\mathrm{~K} 251+260$ & 26.2 & 18.8 & 25.9 & 43.3 & 43.9 \\
\hline \multicolumn{2}{|c|}{ Design strength } & 25 & \multicolumn{2}{|c|}{25} & \multicolumn{2}{|c|}{40} \\
\hline
\end{tabular}

treatment. The foaming capacity and compressive strength of the No. 15 grout are $1173 \%$ and $26.79 \mathrm{MPa}$, respectively. The No. 15 grout not only exhibits a certain expansibility but also exhibits a higher compressive strength. As a result, the No. 15 grout was selected to grout the centre of the damaged track bed to increase the strength and lift the bed.

5.4. Evaluation of Grout Effects. After the construction, the grouting quality is evaluated to determine whether the project has reached the expected target. After the completion of construction, the grout quality is tested every other month a total of four times. A comparison between the fourth test result and the leakage before grouting is shown in Table 11. According to the results in Table 11, no leakage of water occurred on the surface of the track bed after grouting and no mud appeared in the drainage ditch. The four detections did not observe frost boiling and mud in the tunnel, indicating that the leakage in the damaged area of the track bed was eliminated.

The compressive strengths of the inverted arch, filling layer, and monolithic track bed in some sections of the tunnel were measured by ultrasonic testing, resiliometer testing, and core sample detection. The compressive strengths of each section before and after grouting are shown in $\mathrm{Ta}$ ble 12. As shown in the table, the strength of the tunnel filling layer before grouting is less than design strength. This far causes irregular subsidence of the track bed. After the reinforcement of grout, the strength of each part was obviously improved. Among them, the grout effect in the filling layer is the most obvious, with a compressive strength greater than the design requirements. This result shows that grout reinforcement can effectively improve the strength of the filling layer and track bed. At the same time, eight monitoring points were selected equidistantly and symmetrically from left to right in the $\mathrm{K} 251+200$ to $\mathrm{K} 251+240$ section, and the position near the top surface of the track bed outside the rail was monitored for subsidence for almost four months. The curve of the track bed subsidence at the eight monitoring points of the tunnel base versus time is shown in Figure 5. Based on the image, the height of the track bed at each monitoring point has essentially not changed, indicating that the track bed as a whole has stabilized and that the tunnel basement distress has been eliminated.

Through the assessment of grout quality, the No. 4 and No. 15 grout were found to effectively solve the issues of tunnel seepage and basement distress and ensure the safe and normal operation of the train. 


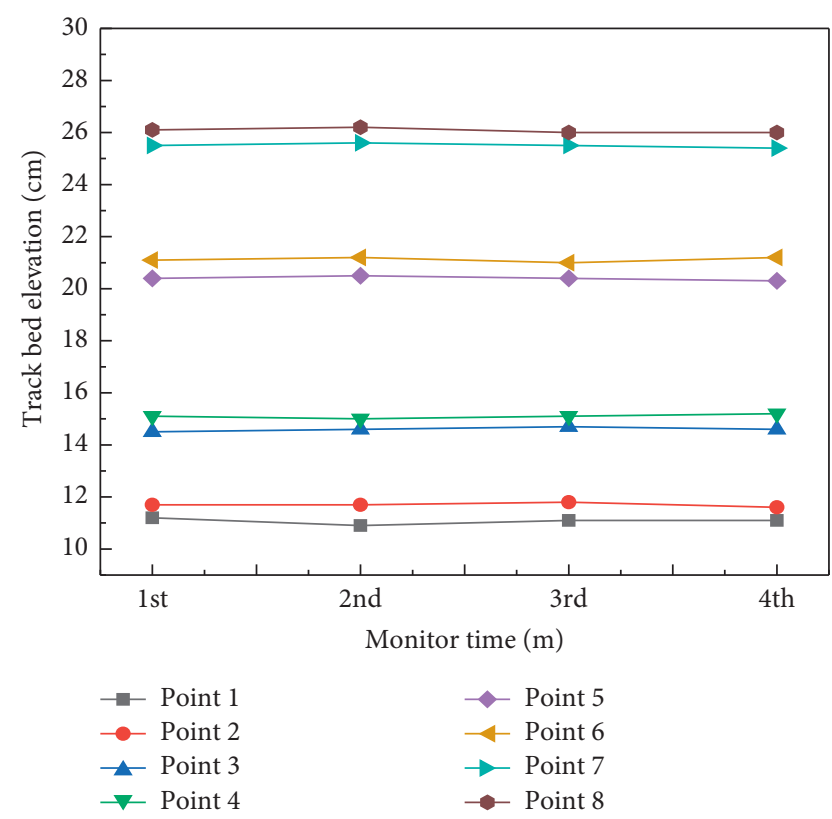

Figure 5: Time-dependent curves of track bed elevation.

\section{Conclusions}

(1) By consulting the literature and optimizing comparisons, we determine an appropriate raw material for a new grout. The main agent is polyaryl polymethylene isocyanate PAPI*135C Polymeric MDI, the auxiliary agent is a mixture of polyether polyol 4110 and 6110 , the catalyst is a mixture of triethylamine and dibutyltin dilaurate, the foam stabilizer is polysiloxane-polyoxyalkylene ether copolymer, the solvent is xylene, and water content equal to $3 \%$ of the total mass of the main and auxiliary agents mixture is added as the inducing reagent.

(2) An orthogonal design was used to design the specific ratios of main agent, auxiliary agent, catalyst, foam stabilizer, and solvent of the grout. Through the testing of density, viscosity, curing time, foaming capacity, and compressive strength of consolidations and environmental protection, three reasonable grout proportion schemes were determined: the No. 3 grout, in which the mass ratio of the main and auxiliary agents is $1: 1$, the amount of catalyst is $0.5 \%$ of the total mass of the main and auxiliary agents mixture, foam stabilizer is $1.5 \%$, and the solvent is $15 \%$; the No. 4 grout, in which the mass ratio of main and auxiliary agents is $1: 1$, catalyst is $0.75 \%$, foam stabilizer is $2 \%$, and the solvent is $20 \%$; and the No. 15 grout, in which the mass ratio of main agent to auxiliary agent is $4: 1$, catalyst is $0.5 \%$, foam stabilizer is $1 \%$, and the solvent is $20 \%$.

(3) The No. 4 grout has a viscosity of $663 \mathrm{MPa} \cdot \mathrm{s}$, a curing time of $137 \mathrm{~s}$, a foaming capacity of $1809 \%$, and a compressive strength of $17.76 \mathrm{MPa} \cdot \mathrm{s}$. It not only exhibits the highest foaming capacity among the groups and can be effectively injected into small gaps in the structure but also is suitable for treating tunnel leakage. The No. 15 grout has a viscosity of $281 \mathrm{MPa} \cdot \mathrm{s}$, a curing time of $98 \mathrm{~s}$, a foaming capacity of $1173 \%$, and a compressive strength of $26.79 \mathrm{MPa}$. It not only has a high compressive strength and can effectively fill and reinforce the structure but also is suitable for reinforcing the tunnel structure. The No. 3 grout has a viscosity of $663 \mathrm{MPa} \cdot \mathrm{s}$, a curing time of 119 s, a foaming capacity of $1589 \%$, and a compressive strength of $20.16 \mathrm{MPa}$. Its foaming capacity and compressive strength are intermediate between those of groups 4 and 15. Therefore, it is suitable for treating tunnel distress requiring seepage prevention, leakage stoppage, and reinforcement.

(4) To treat the leakage and track bed distress in an existing railway tunnel, this study suggests that No. 4 grout, with its excellent fluidity and expansibility, should be selected for curtain grout at the entrance of the tunnel basement fissure water, while No. 15 grout, with its strong reinforcement, should be selected for reinforcement of the track bed. After the construction, the tunnel has been continuously monitored for more than 4 months. Monitoring results show that track bed sinking and frost boiling have been successfully treated in the tunnel.

Through research and analysis of laboratory tests, this paper determined three reasonable proportioning schemes of new grout and provided the distress types suitable for the three schemes. By studying the practical applications of grout through field tests, we finally determined that the new grout can be used to treat distresses such as leakage and basement settlement of existing railway tunnels.

\section{Data Availability}

The data used to support the findings of this study are included within the article.

\section{Conflicts of Interest}

The authors declare that they have no conflicts of interest.

\section{Acknowledgments}

The work described herein was supported by the Central University Special Funding for Basic Scientific Research Business Expenses (no. 300102258401), the Fundamental Research Funds for the Central Universities, CHD (no. 300102219219), and the Key Laboratory for Bridge and Tunnel of Shaanxi Province.

\section{References}

[1] J. Wang, Q. Yang, and Y. Jiang, "Research on water leakage prevention and control techniques in cut tunnel of highspeed railway in rich water zone," Chinese Journal of Underground Space and Engineering, vol. 11, no. 6, pp. 1627$1632,2015$. 
[2] S. Zhou, X. Li, C. Ji, and J. Xiao, "Back-fill grout experimental test for discharged soils reuse of the large-diameter size slurry shield tunnel," KSCE Journal of Civil Engineering, vol. 21, no. 3, pp. 725-733, 2017.

[3] D. Zhang, L. Ran, and J. Yan, "Leakage-Induced ground and tunnel response considering the effect of grouting," Journal of Tongji University for Natural Science, vol. 45, no. 4, pp. 495-503, 2017.

[4] J. Yang, "On grouting treatment for leakage water of deep buried tunnels in water rich area," Highway Engineering, vol. 39, no. 5, pp. 209-214, 2014.

[5] J. Lai, X. Wang, J. Qiu, J. Chen, Z. Hu, and H. Wang, "Extreme deformation characteristics and countermeasures for a tunnel in difficult grounds in southern Shaanxi, China," Environmental Earth Sciences, vol. 77, no. 19, 2018.

[6] Q. Li, L. Liu, Z. Huang, and G. Yuan, "Residual compressive strength of cement-based grouting material with early ages after fire," Construction and Building Materials, vol. 138, pp. 316-325, 2017.

[7] Q. Xue, J.-S. Li, and L. Liu, "Experimental study on antiseepage grout made of leachate contaminated clay in landfill," Applied Clay Science, vol. 80-81, pp. 438-442, 2017.

[8] P. Tu and X. Wang, "Strength deterioration and service life research on subsea tunnel grouting materials," Journal of Engineering Geology \& Hydrogeology, vol. 38, no. 1, pp. 65-68, 2011.

[9] G. Sowmini and K. B. Anand, "Properties of cement grout modi fied with ultra-fine slag," Frontiers of Structural and Civil Engineering, vol. 12, no. 1, pp. 58-66, 2018.

[10] J. Yoon and C. S. El Mohtar, "Groutability of granular soils using bentonite grout based on filtration model," Transport in Porous Media, vol. 102, no. 3, pp. 368-385, 2014.

[11] K. Masumoto, Y. Sugita, T. Fujita, J. B. Martino, E. T. Kozak, and D. A. Dixon, "A clay grouting technique for granitic rock adjacent to clay bulkhead," Physics and Chemistry of the Earth, Parts A/B/C, vol. 32, no. 8-14, pp. 691-700, 2007.

[12] S. Kazemian, B. B. K. Huat, A. Prasad, and M. Barghchi, "A review of stabilization of soft soils by injection of chemical grouting," Australian Journal of Basic and Applied Sciences, vol. 4, no. 12, pp. 5862-5868, 2010.

[13] L. E. Sverdrup, A. E. Kelley, M. Weideborg, K. E. Ødegård, and E. A. Vik, "Leakage of chemicals from two grouting agents used in tunnel construction in Norway: monitoring results from the tunnel romeriksporten," Environmental Science \& Technology, vol. 34, no. 10, pp. 1914-1918, 2000.

[14] J. Qiu, T. Yang, X. Wang, L. Wang, and G. Zhang, "Review of the flame retardancy on highway tunnel asphalt pavement," Construction and Building Materials, vol. 195, pp. 468-482, 2019.

[15] X. Yang and Y. Yu, "Application of cement - silicate double solution grouting in loess tunnel construction," China Journal of Highway Transport, vol. 17, no. 2, pp. 68-72, 2004.

[16] F. Wang, Y. Fan, and C. Guo, "Practice on non-water reacted polymer grouting treatment to seepage," Journal of Hydroelectric Engineering, vol. 37, no. 10, 2018.

[17] L. Li, S. Li, and J. Cui, "Experimental research on chemical grout for treating water inrush in rock mass," Rock and Soil Mechanics, vol. 30, no. 12, pp. 3642-3648, 2009.

[18] C. Vipulanandan, M. B. Kazez, and S. Henning, "Pressuretemperature-volume change relationship for a hydrophilic polyurethane grout," Proceedings of the Grouting and Deep Mixing 2012pp. 1808-1818, ASCE, New Orleans, LA, USA, February 2012.
[19] F. Sha, R. Liu, S. Li et al., "Application on different types of cementitious grouts for water-leakage operational tunnels," Journal of Central South University, vol. 47, no. 12, pp. 4163-4172, 2016.

[20] H. Dai, "Prevention and treatment of invert heaving and lining cracking induced by water disasters in operating railway tunnels," Modern Tunnelling Technology, vol. 53, no. 3, pp. 202-206, 2016.

[21] Q. Wang and H. Sun, "Traffic structure optimization in historic districts based on green transportation and sustainable development concept," Advances in Civil Engineering, vol. 2019, Article ID 9196263, 18 pages, 2019.

[22] L. Wang, D. Zhou, J. Wu, and J. Yang, "The hazard analysis and the treating measures of the voids in the composite lining of railwa tunnels," China Railway Science, vol. 32, no. 5, pp. 56-63, 2011.

[23] China National Standards, Polyurethane Grouting Matertials: JC/T. 2041-2010, China National Standards, Beijing, China, 2010.

[24] China National Standards, Standard Examination Methods for Drinking Water-Metal Parameters: GB/T. 5760.6-2006, China National Standards, Beijing, China, 2006.

[25] X. Yang, K. Zheng, T. Chen, and S. He, "A molding mould for polyurethane grouting material specimen,” 2018.

[26] J. Yang and G. He, "Analysis on disease of tunnel leakage and level division standard," China Concrete Cement Production, vol. 16, no. 1, pp. 76-79, 2017.

[27] Z. Xiaodong, "Treatment of tunnel lining cracks and water leakage in operation tunnels," Journal of Water Resources and Architectural Engineering, vol. 16, no. 3, pp. 201-205, 2018. 